\title{
La alfarería del Tardío Prehispánico del Valle del Bolsón (Catamarca, Argentina): ¿producción local o alóctona?
}

\author{
Verónica Puente*, Rita Plák y Rodrigo Invernizzi* \\ "Consejo Nacional de Investigaciones CientíficaS y Tecnológicas, Laboratorio de \\ Arqueología, Universidad Nacional de Mar del Plata, Argentina. \\ vpuente78@yahoo.com.ar. "* Técnicas Analíticas Nucleares, Comisión Nacional \\ de Energía Atómica, Argentina. rpla@cae.cnea.gov.ar
}

\begin{abstract}
Resumen
En este trabajo se presentan los resultados obtenidos en los estudios de procedencia de conjuntos cerámicos recuperados en dos asentamientos conglomerados del valle del Bolsón (Belén, Catamarca, Argentina) vinculados a ocupaciones del tardío prehispánico (ca. 900-1600 DC). Las muestras estudiadas corresponden principalmente a cerámica pintada en negro sobre rojo reconocida como de estilo Belén, en menor medida ordinaria y excepcionalmente negro sobre crema y ante. Se complementaron análisis petrológicos y análisis por activación neutrónica instrumental realizados a la alfarería y a materias primas adecuadas para la producción alfarera muestreadas en la región. Se concluye que un grupo mayoritario de piezas fueron elaboradas con arcillas y arenas procedentes de la región bajo estudio. Asimismo, se destacan similitudes composicionales entre la vajilla recuperada en ambos asentamientos a pesar de las diferencias logísticas y estratégicas de emplazamiento. Los resultados generados son un importante aporte al tema de la producción alfarera a escala suprarregional dado que evidencian la coexistencia de distintos locus de producción cerámica en el oeste catamarqueño durante el lapso temporal estudiado.
\end{abstract}

Palabras clave: cerámica, tardío prehispánico, procedencia, análisis de activación neutrónica, petrografía.

The Late Prehispanic pottery of the Bolsón Valley (Catamarca, Argentine): local or allochthonous production?

\begin{abstract}
The results obtained in the study of the provenance of ceramic recovered in two conglomerates settlements of the valley of El Bolsón (Belén, Catamarca, Argentina) linked to prehispanic late occupations (ca. 900-1600 AD) are given. The samples analyzed correspond mainly to Belén style ceramic, in lesser frequency to ordinary, and exceptionally to black over cream and beige. This study combined petrological and neutron instrumental activation analysis made in both kind of samples, archaeological pottery and local raw materials. It is concluded that a majority of archaeological pottery were made with clay and sand from the region. Further the logistical and strategic differences that had both settlements, these show similarities between the compositional pottery that was recovered in the same. These results are an important contribution to the subject of production pottery to macroscale, that evidences the coexistence of different locus of ceramic production in the western Catamarca during the period studied.
\end{abstract}

Keywords: pottery, prehispanic late, provenance, neutron activation analysis, petrography.

El valle del Bolsón (Belén, Catamarca, Argentina) se emplaza en un área intermedia entre ambiente de puna y de valles, motivo por lo cual se considera que funcionó como una zona de interacción y tránsito entre ambientes diferenciados, donde coexistieron tanto ocupaciones permanentes como otras generadas por prácticas de movilidad interregional (Korstanje 2005). Dentro de los sitios identificados para el tardío prehispánico o post formativo ${ }^{1}$ (ca. 900-1600 D.C.) se encuentran bajo

\footnotetext{
1 Las categorías de post formativo y tardío prehispánico se utilizan como sinónimos para hacer referencia al lapso temporal comprendido entre ca. 900-1600 D.C. La primera de ellas es tomada de Quiroga (2002).
}

estudio dos asentamientos de ocupación permanente que manifiestan, a partir de sus características arquitectónicas y de emplazamiento, haber cumplido roles diferentes dentro de la dinámica particular del valle. Por un lado, La Angostura es un sitio agregado de carácter residencial y agrícola, cuya ocupación se distribuyó en sectores espacialmente discontinuos (Quiroga 2002). En cambio, el sitio El Duraznito se emplaza en la cima de un jasi -zona desnuda de vegetación-, es de difícil acceso y se halla limitado por precipicios prominentes, a partir de lo cual se plantea que su ubicación se vincula a estrategias de defensa en momentos de conflicto regional y/o suprarregional (Quiroga y Martínez 2013). 
Los restos cerámicos recuperados en ambos asentamientos fueron estudiados desde una escala microsocial, acercamiento que permitió a través del estudio de la variabilidad de modos de hacer -i.e. elecciones técnicas realizadas por los alfareros a lo largo de la cadena operativa- a nivel intra sitio e inter sitio, contribuir al conocimiento de las prácticas cotidianas en las que individuos y grupos sociales elaboraron y usaron los objetos (Puente 2011a). Así desde la perspectiva que entiende a la tecnología como una práctica social de producción de sentido en la que se imbrican aspectos sociales, materiales y simbólicos (Dobres 1999; Lemonnier 1992) y, a través de la combinación de estudios de pastas y estéticos -orientados a reconstruir la apariencia visual de las piezas- se identificó el predominio de dos tradiciones de elaboración alfarera en el valle (Puente 2011a, 2012a, 2012b). Una de ellas corresponde a las piezas de estilo Belén, las cuales se caracterizan por haber sido elaboradas con pastas con abundantes inclusiones de vidrio vesicular y cuarzo, a diferencia de la alfarería ordinaria, negro sobre crema y tricolor que fue manufacturada con temperante de tiesto molido o chamote (Puente 2011a, 2012b).

En el marco de estas investigaciones se planteó la necesidad de determinar por un lado, si la cerámica estudiada había sido elaborada con materias primas locales o alóctonas y, además, si existían diferencias en este aspecto entre los distintos conjuntos y sitios investigados. Para resolver este problema, se generó una base de datos sobre las materias primas aptas para la elaboración de piezas cerámicas disponibles en la región: arcillas $^{2}$ y sedimentos no plásticos. Posteriormente, se realizaron análisis mineralógicos (petrográficos) y químicos (activación neutrónica instrumental) a las materias primas muestreadas y a una muestra numerosa de fragmentos cerámicos, correspondientes principalmente a piezas de estilo Belén y a alfarería ordinaria con el propósito de analizar su procedencia. En este trabajo se detallan los resultados obtenidos en dichas instancias de análisis y se plantea la procedencia local de la mayoría de los conjuntos cerámicos utilizados en la región durante el lapso temporal trabajado.

\section{Los estudios de procedencia cerámica del tardío prehispánico en la región valliserrana}

En los últimos años, los estudios de procedencia de la alfarería post formativa han sido un tópico de interés en el área valliserrana del NOA y puna aledaña. La aproximación a este tema ha vinculado la información contextual de

\footnotetext{
2 Debido a los procesos de depositación y formación, los depósitos -primarios o secundarios- de minerales de arcilla (grupo de los argilominerales) siempre contienen impurezas (Shepard 1957). Estas pueden ser clastos líticos, minerales y materia orgánica en proporciones y tamaños diversos. En este trabajo con el término "arcilla" se hace referencia a dicha mezcla natural y con la categoría "arena" a los depósitos conformados exclusivamente por otros clastos líticos y minerales cuyo tamaño varía principalmente entre 0,062 mm y $4 \mathrm{~mm}$ (según escala de Udden-Wentworth).
}

los hallazgos con datos obtenidos a través de técnicas analíticas mineralógicas y fisicoquímicas diversas. Entre ellas, cabe destacar los análisis por activación neutrónica instrumental (AANI) y en algunos casos en combinación con estudios petrográficos.

La técnica de AANI fue implementada con gran intensidad en diversas investigaciones realizadas por Ratto y su equipo de trabajo, principalmente, para analizar aspectos vinculados a la producción y distribución alfarera en asentamientos ubicados en el bolsón de Fiambalá y la puna transicional de Chaschuil (Dpto. Tinogasta, Catamarca) (De la Fuente 2007; Orgaz et al. 2007; Plá y Ratto 2003; Ratto et al. 2002a, Ratto et al. 2002b; Ratto et al. 2004; Ratto et al. 2007; Ratto y Plá 2009). Los estudios de procedencia realizados por dicho equipo combinaron principalmente la información recabada a través de análisis con lupa binocular y microscopio petrográfico de las pastas cerámicas y AANI realizados tanto a fragmentos de alfarería como a materias primas arcillas y antiplásticos- locales. También realizaron análisis de DRX para conocer la composición mineralógica de los depósitos fangoarcillosos (De la Fuente 2007, 2010; Ratto et al. 2002a; Ratto et al. 2004; Ratto et al. 2010; Feely 2010, 2011). Como resultado de dichos estudios se planteó que el área de La Troya funcionó como un locus de producción alfarera durante momentos formativos, pre-incas e incas (De la Fuente 2007; Ratto et al. 2002; Ratto et al. 2004; Ratto et al. 2007; Ratto et al. 2010). Se determinó que estilos incaicos, cerámica ordinaria y de estilos tardíos, principalmente Sanagasta y Abaucán, fueron manufacturadas en el sitio Batungasta y con materias primas extraídas de la cuenca media del río Troya (De La Fuente 2007). Asimismo ejemplares de estilo Belén o que poseen a nivel iconográfico un gran sincretismo con la cerámica de dicho estilo se consideraron como de elaboración local (De la Fuente 2007; Ratto et al. 2007). Esta interpretación se sustenta además, por el hallazgo de fragmentos sobrecocidos asociados a numerosos hornos para la cocción de cerámica ubicados en la periferia del sitio Batungasta. Esta evidencia, por sus características de preservación y escala, es única en el Noroeste argentino.

Análisis por activación neutrónica en combinación con estudios petrográficos fueron aplicados para estudiar la procedencia de alfarería post formativa en el valle de Tafí. Si bien allí no hay registros de contextos de cocción o manufactura alfarera, los resultados alcanzados permitieron detectar una fuerte asociación entre dos depósitos arcillosos y cerámica de estilos diversos -Santa María, Yocavil, Famabalasto, Inca y tosca-, motivo por el cual se sugiere su utilización en la manufactura (Páez 2010).

El tema de la procedencia de alfarería tardía también se está investigando en el valle de Hualfín. Por el momento los estudios se han centrado en análisis petrográficos (Iucci 2013; Zagorodny et al. 2010). A partir de la 
correspondencia entre la naturaleza mineralógica de las inclusiones no plásticas presentes en la cerámica Belén con la geología regional, se cree que posiblemente las materias primas para su manufactura fueron obtenidas en las formaciones locales. Este planteo se basa en el análisis por lupa binocular de la arena que trasporta el río Hualfin y distintos colectores, y en identificaciones realizadas por cortes delgados sobre sedimentos del río Corral Quemado (Iucci 2013; Zagorodny et al. 2010). Los estudios de AANI se encuentran en curso (lucci com. pers.).

Análisis petrográficos y por AANI también se combinaron para evaluar si la cerámica de estilo Famabalasto Negro Grabado recuperada en el valle de Yocavil y en la sierra y valle del Cajón presentaba correspondencia composicional entre sí y, en este sentido, si había sido elaborada con materias primas procedentes de una misma región (Palamarczuk 2011). Hasta el momento no se cruzó dicha información con estudios mineralógicos y químicos de materias primas regionales. Cabe destacar que en el sitio Rincón Chico (valle de Yocavil) se recuperaron fragmentos cerámicos sin cocer e instrumentos que posiblemente fueron utilizados en la manufactura cerámica, entre ellos, alisadores realizados con fragmentos cerámicos reciclados (Palamarczuk 2008) similares a los recuperados en el sitio El Duraznito.

En síntesis, a pesar de la ausencia o escasez de contextos primarios de producción alfarera, la aplicación de técnicas analíticas mineralógicas y fisicoquímicas combinadas permite determinar si las piezas estudiadas fueron elaboradas con las mismas materias primas y, además, si éstas proceden de la región en que las vasijas fueron halladas. Los antecedentes generados por distintos grupos de trabajo permiten reconocer que en el bloque temporal que representa el tardío prehispánico coexistieron distintos locus de elaboración cerámica, de características y escalas diversas.

\section{Los conjuntos cerámicos del valle del Bolsón}

Los conjuntos cerámicos recuperados en los sitios La Angostura y El Duraznito proceden principalmente de recolecciones superficiales sistemáticas realizadas en recintos de habitación y sectores extramuros. Dados los procesos de formación de ambos sitios, el material hallado en estratigrafía es escaso, aspecto que dificulta el hallazgo de muestras factibles de ser datadas por técnicas absolutas. Si bien hasta el momento solo se dispone de un fechado radiocarbónico (390 \pm 70 años A.P) para el sitio La Angostura ${ }^{3}$, a partir de la combinación de las características de la planta arquitectónica y de la cerámica de ambos asentamientos se plantea un lapso de ocupación general que se ubica entre 900 y 1600 años D.C al que denominamos tardío prehispánico o post formativo (Quiroga 2002, 2010). Esta tendencia a

\footnotetext{
3 El fechado para el sitio el Duraznito se encuentra en proceso de análisis.
}

tomar un bloque temporal amplio es coherente con lo sucedido a escalas espaciales mayores, particularmente en los valles vecinos de Yocavil y Hualfín. Para el primer caso se plantea que durante el bloque temporal mencionado se superponen diversas ocupaciones donde la cultura material se presenta sin solución de continuidad dificultando discriminar períodos cronológicos más acotados (Marchegiani et al. 2009). Por su parte, en el valle de Hualfín los fechados correspondientes a las ocupaciones tardías se extienden hasta mediados del siglo XVII (Quiroga 2011).

Los conjuntos cerámicos de ambos sitios son muy similares entre sí en lo que respecta a aspectos estéticos visuales como a la tecnología de sus pastas. La diferencia principal se establece en que la muestra recuperada en El Duraznito (N: 1259 fragmentos) es más numerosa y presenta mejores condiciones de conservación que la de La Angostura (N: 551 fragmentos). A partir de las características de tratamiento de superficie y color de los fragmentos se establecieron grupos de referencia generales: a) La Angostura: negro sobre rojo (60,55\%), ordinario $(33,63 \%)$, negro sobre crema $(5,10 \%)$, ante fino $(0,72 \%)$; b) El Duraznito: negro sobre rojo $(36,60 \%)$, ordinario $(49,48 \%)$, negro sobre crema $(12,89 \%)$, negro, rojo y crema $(1,03 \%)$. (Figura 1$)$

La mayoría de los fragmentos negro sobre rojo pertenecieron a piezas identificadas como de estilo Belén. Estos representan la variabilidad morfológica reconocida para este conjunto a partir de piezas de colección (Puente y Quiroga 2007): Forma 1 o urnas, Forma 2 o pucos (de

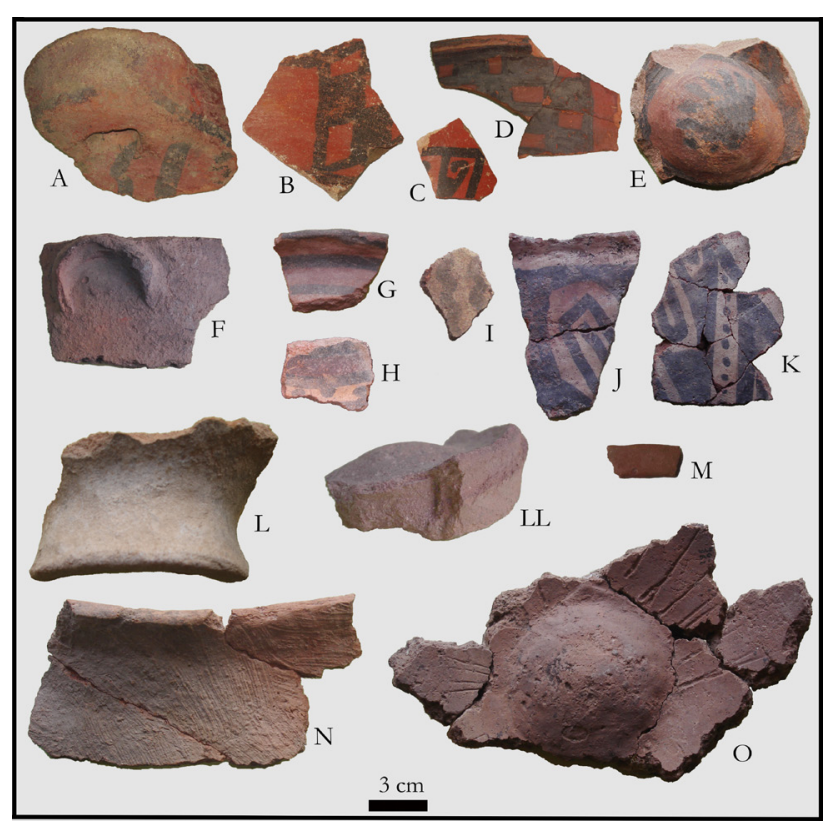

Figura 1. Grupos de referencia: negro sobre rojo $(A, B, C, D, E)$; negro sobre crema (I, J, K); negro, rojo y $\operatorname{crema}(G, H)$; ante fino $(L L, M)$; ordinario $(\mathrm{F}, \mathrm{L}, \mathrm{N}, \mathrm{O})$.

Figure 1. Reference Groups: Black on red (A, B, C, D, E); black on cream $(I, J, K)$; black, red and cream $(G, H)$; ante fine $(L L, M)$; coarse $(F, L, N, O)$. 


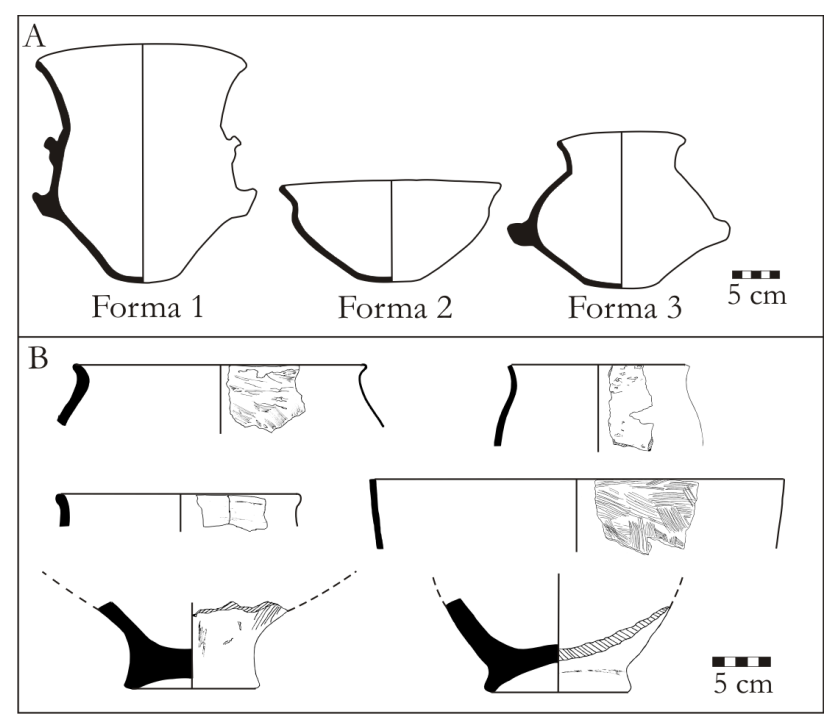

Figura 2. Formas representativas de los conjuntos predominantes en el valle.

Figure 2. Representative forms of the predominant pottery sets in the valley.

contorno simple e inflexionado) y Forma 3 o cántaro (Figura 2A). Con respecto al grupo ordinario, se trató de piezas de paredes gruesas (en promedio $1 \mathrm{~cm}$ de espesor), con terminaciones irregulares y superficies rugosas y/o peinadas. Asimismo, en fragmentos correspondientes a 25 piezas diferentes se identificaron representaciones plásticas geométricas realizadas principalmente por incisión y en menor medida aplicación de pastillaje. A partir de los fragmentos diagnósticos de formas se observa el predominio de piezas de borde evertido con diámetros de boca variables $(13-56 \mathrm{~cm})$ sin cuello o con cuellos cortos, con cuerpos de diámetros mayores a la boca y de forma sub-globular, ovaloide y elipsoide. Las superficies de apoyo son en su mayoría bases de forma cóncava, algunas con pie hiperboloide y de manera excepcional trípodes y en forma de cono (Puente 2012b) (Figura 2B).

Con respecto a los grupos menos representados, algunos ejemplares negro sobre crema y negro, rojo y crema se identificaron como pertenecientes a pucos y urnas de estilo Santamariano. En otros casos no fue posible establecer una asociación estilística concreta dado el estado de conservación de los fragmentos. Por último, del grupo ante fino si bien es muy poco lo que se puede decir de las piezas representadas, se destacan una base cóncava y un fragmento de asa cinta.

Las pastas de los fragmentos recuperados en ambos sitios que poseían un tamaño superior a $2 \mathrm{~cm}$ de lado (N: 1741) fueron estudiadas en primera instancia con lupa binocular de bajos aumentos. Este análisis permitió establecer grupos generales a partir de las características de las inclusiones y textura de la matriz. Posteriormente, se analizó con microscopio petrográfico una muestra representativa (N: 150) de dicha variabilidad y correspondiente a vasijas diferentes ${ }^{4}$ procurando incorporar ejemplares de las diversas categorías morfológicas: 69 negro sobre rojo, 66 ordinarios, 13 negro sobre crema, uno ante fino y uno tricolor. De este modo, en esta etapa del trabajo la unidad de análisis pasó de ser el fragmento a la vasija como ejemplar. Los resultados alcanzados evidencian la incorporación de tiesto molido o chamote por un lado y, la utilización de arenas con altos contenidos de vidrio vesicular y cuarzo por el otro, diversidad que materializa la presencia de dos tradiciones de elaboración en la región (Puente 2011a, 2012a, 2012b). El tiesto molido fue incorporado en el $80,3 \%$ de los ejemplares ordinarios, en el $92,3 \%$ del grupo negro sobre crema, en todo el grupo tricolor y ante fino ${ }^{5}$. La diferencia principal en las pastas se establece con la cerámica de estilo Belén, la cual posee pastas muy homogéneas en cuanto a la naturaleza de las inclusiones -altos porcentajes de cuarzo monocristalino y vidrio vesicular entre otros clastos líticos y minerales- y el tiesto molido está ausente en el 94,11\% de los ejemplares.

\section{Materiales y métodos}

Se considera como producción local a la alfarería que posee correspondencia química y mineralógica con las materias primas recuperadas en el valle. Esta determinación implicó la combinación de las características geológicas de la región y la información generada a partir de distintas herramientas analíticas: petrografía y análisis por activación neutrónica.

El análisis petrológico implica la comparación de la información composicional obtenida a partir del análisis petrográfico por cortes delgados de cerámica arqueológica y de sedimentos locales. Si bien este estudio no permite determinar la naturaleza mineralógica de las arcillas, nuestro propósito fue observar qué minerales y clastos líticos no arcillosos acompañan a estos sedimentos. Esto cobra sentido al considerar que: a) los alfareros pueden utilizar los depósitos arcillosos y aprovechar sus cargas naturales sin el posterior agregado de material antiplástico, b) si bien, el sedimento arcilloso que contiene naturalmente inclusiones minerales no plásticas puede ser tamizado por los artesanos, en la mayoría de los casos no se elimina la totalidad de los mismos. Asimismo, los depósitos arenosos son fuentes de posibles antiplásticos. De este modo, se comparó la identificación de las inclusiones presentes en la cerámica y estudiadas previamente (Puente 2011a, 2011b, 2012a) con la misma información obtenida de un conjunto de sedimentos muestreados en distintos depósitos del valle,

\footnotetext{
4 Dado que el material es fragmentario y procede en su mayoría de la superficie de los sitios, la metodología utilizada para seleccionar fragmentos correspondientes a distintas vasijas combinó la información del lugar de hallazgo, la sección y tipo de pieza que representa y el tipo de pasta.

5 Los porcentajes están calculados sobre la base de la muestra analizada con microscopio petrográfico.
} 
con el propósito de determinar si existía concordancia entre ellos. Para el análisis microscópico de los sedimentos cada muestra fue consolidada con resina y se elaboraron "pastillas" que permitieron realizar el corte delgado y la posterior observación. Esta instancia de investigación brinda información fundamental para comparar la geología regional con las características y el origen geológico de las inclusiones presentes en la pasta y, en este sentido, constituye una primera etapa en los estudios de procedencia (Cremonte et al. 2007; Shepard 1957; Stoltman 2001).

Con respecto al AANI es una técnica analítica nuclear basada en las transformaciones que tienen lugar en el núcleo de los átomos como resultado de reacciones nucleares causadas por neutrones. Es una técnica de gran exactitud, precisión y sensibilidad, que brinda información sobre las concentraciones totales de un gran número de elementos químicos presentes en la muestra. Por estos motivos actualmente se considera una de las mejores técnicas de caracterización química multielemental para ser aplicada a estudios de procedencia (Bishop 2003; Plá 2009). El objetivo de la utilización de esta técnica fue comparar un conjunto de fragmentos cerámicos -representativos de la diversidad mineralógica determinada previamente a partir de los análisis petrográficos- y distintas arcillas muestreadas en el Valle del Bolsón con el propósito de obtener una caracterización química multielemental que permitiera establecer inferencias sobre la procedencia local o no local de los conjuntos. Las muestras de arcillas analizadas fueron previamente sometidas a una cocción controlada en un horno cerrado que no superó los $900^{\circ 6}$ y luego las briquetas fueron irradiadas. Los análisis fueron realizados en la Comisión Nacional de Energía Atómica en el Centro Atómico Ezeiza por el grupo de trabajo de Técnicas Analíticas Nucleares.

\section{Las materias primas locales}

\section{Características geológicas del Valle del Bolsón}

Las características geológicas del Valle del Bolsón (2652' a $27^{\circ} \mathrm{LS}, 66^{\circ} 49^{\prime} \mathrm{LO}$ ) corresponden a un ambiente típico de Sierras Pampeanas (González Bonorino 1950; Turner 1973). La ubicación de los sitios arqueológicos estudiados se vincula con dos formaciones litológicas de origen terciario correspondientes al Grupo El Bolsón (MiocenoPlioceno), representadas por un conjunto de sedimentos continentales con intercalación de origen volcánico: 1) La Formación El Áspero está integrada por una facie lávica y una facie intrusiva en donde se destacan elementos de

\footnotetext{
${ }^{6}$ Esta tarea fue parte de la experimentación realizada con las arcillas locales con motivo de evaluar su comportamiento durante el proceso de manufactura (Puente 2011a). Se sabe que la temperatura a la que fue horneada la cerámica puede generar cambios en su composición. Sin embargo, la cocción por debajo de los $1000^{\circ}$ (característico de la mayoría de la cerámica prehispánica del actual NOA) no altera los elementos detectados por el AANI (Bishop 2003; Plá 2009; Ratto y Plá 2010).
}

origen piroclástico, brechas y tobas de naturaleza entre andesítica y basáltica. En el valle, predomina la facie lávica formada por brechas (andesitas de color verde azulado, con numerosos fenocristales de anfíbol y plagioclasa) y tobas básicas y ácidas (Turner 1973). 2) La Formación El Cajón (Araucanense) se superpone en concordancia sobre la formación anterior y está integrada por un conjunto de elementos clásticos y volcánicos. En el valle, predominan las areniscas arcósicas gruesas. El material constitutivo es mayormente granítico (puede ser migmatítico), con rodados de pizarra cuarzosa, gneiss milonítico, micacitas y andesita. Presenta bancos de material tufítico y otros de material tobáceo (González Bonorino 1950; Turner 1973).

Asimismo, los asentamientos se vinculan con depósitos de acarreo de consolidación pobre constituidos por sedimentos arenosos con intercalaciones arcillosas y conglomeráticas dispuestas en terrazas (Turner 1973). El río El Bolsón es el recurso hídrico principal del valle y acarrea de $\mathrm{N}$ a S material correspondiente a las formaciones geológicas El Cajón, Loma Corral (Precámbrico, integrada por rocas metamórficas sin aporte magmático) y Chango Real (Precámbrico, conformada por granitos migmatíticos). Por otra parte, los cauces de ríos y arroyos temporarios, tributarios del río $\mathrm{El}$ Bolsón acarrean tanto desde el E como desde el O material de las formaciones El Áspero y El Cajón. Como resultado, el río El Bolsón transporta sedimentos conformados por fragmentos de rocas y minerales de origen diverso: tobas, granitos migmatíticos, rocas sedimentarias, rocas volcánicas y rocas metamórficas.

La estrategia de muestreo de materias primas y las fuentes identificadas

Con el propósito de identificar fuentes de materias primas aptas para ser utilizadas en la manufactura alfarera se complementó la información obtenida a partir de prospecciones geológicas con datos brindados por los pobladores actuales. Para determinar las zonas de prospección se utilizó la información geomorfológica, geológica y arqueológica disponible. En relación con esta última, el criterio inicial fue prospectar la región circundante a los sitios arqueológicos investigados. Posteriormente, la prospección se extendió al resto del sector central y sur del valle. Dado que los depósitos secundarios de arcilla pueden encontrarse en contextos lacustres y aluviales (Rice 1987; Rye 1981) se examinaron las márgenes de cursos de agua permanentes y temporarios. Los depósitos estratificados fueron detectados en perfiles expuestos en terrazas aluviales, barrancos naturales y barrancos artificiales originados por la construcción de la ruta provincial $n^{\circ} 43$ que atraviesa el valle de sur a norte.

A la par de estas tareas, se realizaron entrevistas informales a distintos pobladores de la región con el objeto de obtener información sobre la existencia de 


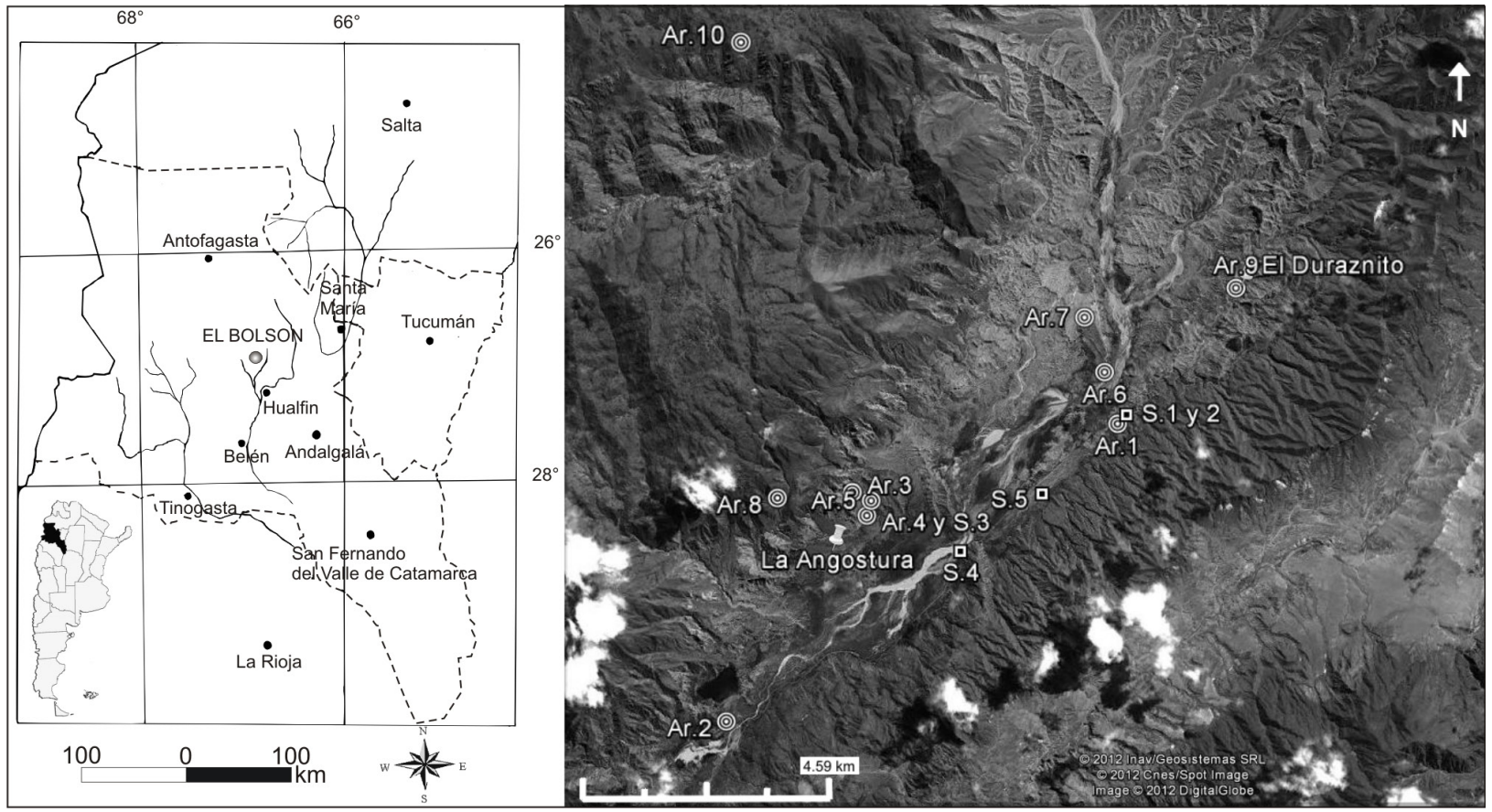

Figura 3. Mapa e imagen satelital de la región con la ubicación de los sitios y las fuentes de materias primas. Mapa modificado de Quiroga (2011).

Figure 3. Map and satellite image of the region with the location of the sites and sources of raw materials. Map after Quiroga (2011).

fuentes de materias primas y modos de elaboración alfarera actuales o del pasado (Puente 2011a). Si bien en la actualidad ya nadie elabora cerámica en el valle se obtuvo información sobre la existencia de tres fuentes de arcilla (Ar.1, Ar.7 y Ar.10).

En total se detectaron y muestrearon 10 fuentes de arcilla y se extrajeron, además, cinco muestras de sedimentos arenosos en distintos sectores del valle (Figura 3, Tabla 1). Todas las muestras fueron georeferenciadas por medio de la utilización de GPS y se evaluó la plasticidad y maleabilidad de las arcillas en el campo. Posteriormente en el laboratorio se realizaron tareas de experimentación y estas propiedades se estudiaron con mayor profundidad junto con el grado de contracción y pérdida de peso que sufrían las materias primas arcillosas luego del proceso de secado y cocción (Puente 2011a).

\section{Estudios petrográficos: características de los sedimentos y comparación con la cerámica}

La naturaleza mineralógica y petrográfica del material no plástico superior a 0,029 $\mathrm{mm}$ es semejante entre los depósitos arcillosos muestreados ${ }^{7}$. Como se observa en la tabla 2 en todos los casos, hay porcentajes significativos de cuarzo monocristalino y de extinción ondulante, plagioclasa, feldespato potásico, biotita, muscovita y minerales opacos. En algunas muestras se identificaron cristaloclastos de anfíbol, piroxeno y cuarzo policristalino

\footnotetext{
7 De la fuente de arcilla Ar.10 se seleccionaron dos muestras para analizar por petrografía (LT3 y LT2) y otras dos (LT1 y LT4) para estudiar por análisis por activación neutrónica.
}

pero en porcentajes muy bajos. El vidrio vesicular (material piroclástico) y los litoclastos volcánicos solo están presentes en proporciones considerables en la muestra Ar.1, junto con los cristaloclastos mencionados.

Considerando las características expuestas, desde el punto de vista petrográfico cualquiera de los depósitos arcillosos muestreados pudo haber sido utilizado en la elaboración de los conjuntos cerámicos de la región, dado que: a) los antiplásticos identificados en las muestras están presentes en la mayoría de los conjuntos cerámicos; b) hay arcillas de matrices microgranosas y no microgranosas similares a los fondos de pasta identificados por petrografía en la cerámica ${ }^{8}$ (Puente 2011a, 2012a). Por otra parte, las inclusiones que vienen junto con las arcillas varían en sus características de esfericidad y redondez, incluso dentro de la misma muestra. Esto ejemplifica claramente que las inclusiones de carácter angular o sub-angular presente en la cerámica no necesariamente son el resultado de la molienda del alfarero.

Por otra parte, a diferencia de las arcillas en las arenas muestreadas no solo se identificaron cristaloclastos sino también litoclastos de orígenes diversos. Se establecieron importantes diferencias entre los depósitos que permitieron conocer la variabilidad local y plantear inferencias en torno a la utilización de determinadas fuentes de antiplástico. Particularmente, en la alfarería Belén predominan los antiplásticos de cuarzo monocristalino, vidrio vesicular, líticos volcánicos, plagioclasa y feldespato potásico.

\footnotetext{
8 La base de datos de petrografía cerámica puede consultarse en Puente 2011a
} 


\begin{tabular}{|c|c|c|c|c|}
\hline Id & Coordenadas & $\begin{array}{l}\text { Naturaleza } \\
\text { del depósito }\end{array}$ & $\begin{array}{l}\text { Formación } \\
\text { geológica }\end{array}$ & Observaciones \\
\hline Ar.1 & $\begin{array}{l}27^{\circ} 00^{\prime} 17.85^{\prime \prime} \text { LS y } \\
66^{\circ} 44^{\prime} 5.17^{\prime \prime} \text { LO }\end{array}$ & Estratificado & El Áspero & $\begin{array}{l}\text { Indicada por uno de los pobladores del } \\
\text { valle. Se utilizaba en tareas escolares. }\end{array}$ \\
\hline Ar.2 & $\begin{array}{l}27^{\circ} 3^{\prime} 18.34^{\prime \prime} \text { LS y } \\
66^{\circ} 48^{\prime} 34.37^{\prime \prime} \text { LO }\end{array}$ & Superficie & Acarreo & Depósito formado por una vega seca. \\
\hline Ar.3 & $\begin{array}{l}27^{\circ} 0^{\prime} 58.62^{\prime \prime} \text { LS y } \\
66^{\circ} 47^{\prime} 6.06^{\prime} \text { LO }\end{array}$ & Estratificado & El Cajón & \\
\hline Ar. 4 & $\begin{array}{l}27^{\circ} 1^{\prime} 13.97^{\prime \prime} \text { LS y } \\
66^{\circ} 46^{\prime} 53.71^{\prime \prime} \text { LO. }\end{array}$ & Estratificado & El Cajón & \\
\hline Ar.5 & $\begin{array}{l}27^{\circ} 11^{\prime} 3.91^{\prime \prime} \text { LS y } \\
66^{\circ} 46^{\prime} 55^{\prime \prime} \text { LO }\end{array}$ & Estratificado & El Cajón & \\
\hline Ar.6 & $\begin{array}{l}26^{\circ} 59^{\prime} 46.47^{\prime \prime} \text { LS y } \\
66^{\circ} 44^{\prime} 13.95^{\prime \prime} \text { LO }\end{array}$ & Estratificado & Acarreo & $\begin{array}{l}\text { Perfil expuesto como resultado de la } \\
\text { construcción de la ruta provincial no } 43 \text {. }\end{array}$ \\
\hline Ar.7 & $\begin{array}{l}26^{\circ} 59^{\prime} 13.4^{\prime \prime} \text { 'LS y } \\
66^{\circ} 44^{\prime} 27.2^{\prime \prime} \text { LO }\end{array}$ & Estratificado & Acarreo & $\begin{array}{l}\text { Indicada por uno de los pobladores del } \\
\text { valle. Se utilizaba en tareas escolares. }\end{array}$ \\
\hline Ar.8 & $\begin{array}{l}27^{\circ} 1^{\prime} 0.80^{\prime \prime} \text { LS y } \\
66^{\circ} 47^{\prime} 6.44^{\prime \prime} \text { LO }\end{array}$ & Superficie & Acarreo & \\
\hline Ar.9 & $\begin{array}{l}66^{\circ} 58^{\prime} 58.26^{\prime \prime} \text { 'L.S. } \\
66^{\circ} 42^{\prime} 43.57^{\prime \prime} \text { 'L.O. }\end{array}$ & Estratificado & El Áspero & \\
\hline Ar.10 & $\begin{array}{l}26^{\circ} 56^{\prime} 41.0^{\prime \prime} \text { "LS y } \\
66^{\circ} 48^{\prime} 03.6^{\prime \prime} \text { LO }\end{array}$ & Estratificado & $\begin{array}{l}\text { Chango } \\
\text { Real }\end{array}$ & $\begin{array}{c}\text { Fuente utilizada por la última alfarera } \\
\text { que habitó la región. Se la conoce como } \\
\text { La Tranca. Se extrajeron } 4 \text { muestras de } \\
\text { distintos sectores del barranco (Ar.10-LT1, } \\
\text { Ar.10-LT2, Ar.10-LT3, Ar.10-LT4). }\end{array}$ \\
\hline S.1 & $\begin{array}{l}27^{\circ} 11^{\prime} 11.64 \text { ” LS y } \\
66^{\circ} 43^{\prime} 58.52^{\prime \prime} \text { LO }\end{array}$ & Superficie & El Áspero & Depósito piroclástico consolidado. \\
\hline S.2 & $\begin{array}{l}27^{\circ} 1^{\prime} 11.66^{\prime} \mathrm{LS} y \\
66^{\circ} 43^{\prime} 59.00^{\prime \prime} \mathrm{LO}\end{array}$ & Estratificado & El Áspero & Depósito piroclástico sin consolidar. \\
\hline S.3 & $\begin{array}{l}27^{\circ} 11^{\prime} 11.96^{\prime \prime} \text { LS y } \\
66^{\circ} 46^{\prime} 54.29^{\prime} \text { LO }\end{array}$ & Estratificado & El Cajón & \\
\hline S.4 & $\begin{array}{l}27^{\circ} 11^{\prime} 31.96^{\prime \prime} \text { LS y } \\
66^{\circ} 45^{\prime} 50.56^{\prime \prime} \text { LO }\end{array}$ & Superficie & $\begin{array}{l}\text { Acarreo Río } \\
\text { el Bolsón }\end{array}$ & Acarreo del río El Bolsón. \\
\hline S.5 & $\begin{array}{l}27^{\circ} 0^{\prime} 59.52^{\prime \prime} \text { LS y } \\
66^{\circ} 44^{\prime} 56.56^{\prime \prime} \text { LO }\end{array}$ & Superficie & Acarreo & Acarreo de cauce hídrico temporario. \\
\hline
\end{tabular}

Tabla 1. Características generales de los depósitos de arcilla y arena. Referencias: Id (identificación), Ar. (arcilla), S. (sedimento-arena).

Table 1. General characteristics of the deposits of clay and sand. References: Id (identification), Ar. (Clay), S. (sediment-sand).

\begin{tabular}{cccccccccccccccc}
\hline & Ar.1 & Ar. 2 & Ar. 3 & Ar.5 & Ar. 6 & Ar.7 & Ar. 8 & Ar.9 & $\begin{array}{c}\text { Ar.10 } \\
\text { LT3 }\end{array}$ & Ar.10 & LT2 & S. 2 & S. 3 & S. 4 & S. 5 \\
\hline Matriz & 61,47 & 84,53 & 84,38 & 70,26 & 83,17 & 97,75 & 79,4 & 74,39 & 73,87 & 91,98 & - & - & - & - \\
Qz & 8,27 & 4,24 & 4,49 & 6,69 & 5,84 & 0,75 & 4,12 & 5,37 & 4,5 & 1,69 & 2,1 & 17,98 & 20 & 0,53 \\
Fk & 1,42 & 0,42 & 1,76 & 3,72 & 1,94 & 0,25 & 0,55 & 8,54 & 3,6 & 0,42 & 0,47 & 29,39 & 6,22 & - \\
Plag & 7,09 & 1,27 & 2,34 & 6,69 & 4,54 & 0,25 & 5,49 & 4,15 & 2,7 & 0,42 & 0,93 & 32,89 & 12,44 & 0,26 \\
Micr & 0,47 & - & - & - & - & - & - & 0,24 & - & - & - & - & 2,44 & - \\
Biot & 1,18 & 3,81 & 2,34 & - & 1,94 & 0,25 & 1,92 & 1,71 & 1,8 & 0,42 & 0,7 & 3,95 & 2 & - \\
M usc & 1,18 & 2,54 & 0,78 & 1,12 & - & 0,25 & 1,92 & 1,46 & 1,8 & 0,63 & - & - & 0,22 & - \\
Cl & - & 0,42 & - & - & - & 0,25 & - & - & - & - & - & - & 0,22 & - \\
Anf & 0,24 & - & 0,39 & 0,74 & 0,64 & - & 0,27 & 0,24 & - & - & 0,12 & 1,75 & 0,22 & - \\
Px & 0,71 & 0,21 & 0,2 & 0,37 & 0,64 & - & 0,27 & - & - & - & - & 1,75 & 1,56 & - \\
Ep & 0,24 & - & 0,2 & - & - & - & 0,27 & 0,24 & - & - & - & 0,44 & 0,67 & - \\
Carb & - & - & - & - & - & - & - & - & - & - & - & - & 0,89 & - \\
Op & 1,18 & 1,91 & 0,78 & 1,49 & - & 0,25 & 1,1 & 0,98 & 0,9 & 3,16 & - & 1,32 & 0,22 & - \\
Vidrio & 5,67 & 0,21 & 0,59 & 0,37 & - & - & 0,55 & 0,98 & - & - & 93,69 & 0,44 & 9,11 & 9,5 \\
L.volc & 9,93 & 0,21 & - & 0,74 & 1,29 & - & 2,2 & 1,71 & - & - & 1,17 & 2,63 & 12,44 & 87,34 \\
L.gr & 0,24 & - & 1,17 & 5,95 & - & - & - & - & - & 0,63 & - & 6,58 & 9,78 & - \\
L.met & 0,71 & - & 0,2 & 1,49 & - & - & 1,92 & - & 10,81 & 0,63 & 0,47 & 0,88 & 15,78 & 2,11 \\
L.sed & - & - & - & - & - & - & - & - & - & - & - & - & - & 0,26 \\
L.alt. & - & 0,21 & 0,39 & 0,37 & - & - & - & - & - & - & 0,35 & - & 5,78 & - \\
R.tam. & $0,03-$ & $0,03-$ & $0,03-$ & $0,03-$ & $0,03-$ & $0,03-$ & $0,04-$ & $0,24-$ & $0,03-$ & $0,03-$ & $0,07-$ & $0,1-$ & $0,03-$ & $0,6-$ \\
mm & 2,24 & 0,35 & 1 & 2,24 & 0,25 & 0,2 & 0,2 & 4 & 1,8 & 1,5 & 1,33 & 2,4 & 1,8 & 3,2 \\
\hline
\end{tabular}

Tabla 2. Análisis modal de los sedimentos estudiados por petrografía.

Referencias: Los valores se expresan en porcentajes. Ar (arcilla), Qz (cuarzo monocristalino), Fk (feldespato potásico), Plag (plagioclasa), Micr (microclino), Biot (biotita), Musc (muscovita), Cl (clorita), Anf (anfibol), Px (piroxeno), Ep (edpidoto), Carb (carbonato), Op (opaco), L.vol (litoclasto volcánico), L.gr (litoclasto granítico), L.met (litoclasto metamórfico), L.sed (litoclasto sedimentario), L.alt (litoclasto alterado), R.tam. mm (rango de tamaños en $\mathrm{mm}$ ).

Table 2. Modal analysis of the sediments examined by thin section petrography.

References: Values are expressed in percentages. Ar (clay), QZ (monocrystalline quartz), Fk (potassium feldspar), Plag (plagioclase), Micr (microcline), Biot (biotite), Musc (muscovite), Cl (chlorite), Anf (amphibole), Px (pyroxene), Ep (edpidoto), Carb (carbonate), Op (opaque), L.vol (volcanic litic), L.gr (granite litic), L.met (metamorphic litic), L.sed (sedimentary litic), L.alt (altered litic), R. tam. mm (range of sizes in mm). 
En menor medida se observa biotita, líticos graníticos, minerales opacos, líticos metamórficos y anfíboles (Puente 2011a, 2012a). Esta combinación de minerales, material piroclástico y rocas de orígenes litológicos diferentes -volcánicos, metamórficos y graníticos- se encuentra presente en el sedimento que acarrea el río El Bolsón (S.4). A su vez, es importante destacar que los clastos y trizas de vidrio vesicular que conforman la arena S.2 poseen las mismas características que los clastos piroclásticos que acarrea el río y que están presentes en esta cerámica y en escasos ejemplares del conjunto ordinario. De este modo, ambas fuentes de antiplástico pueden haber sido utilizadas, tal vez en combinación, para elaborar estas piezas.

Para la mayoría de la cerámica ordinaria y gran parte de la negro sobre crema es difícil establecer conclusiones sobre su procedencia debido a que fueron elaboradas con cantidades abundantes de tiesto molido como temperante. Sin embargo, es posible identificar relaciones con aquellos casos en que el tiesto molido está presente junto con cantidades importantes de clastos líticos y minerales, los cuales coinciden claramente con los presentes en la arena S.4 (río El Bolsón). Asimismo, dentro del conjunto de ejemplares que no poseen tiesto molido (13 ordinarios; uno negro sobre crema), la diversidad petrográfica de las inclusiones también es similar a la identificada en la muestra S.4 (Puente 2011a). De este modo, dado que la naturaleza de las inclusiones no plásticas de gran parte de la alfarería ordinaria concuerda con las materias primas presentes en la región, no se descarta su manufactura local. Solo en cinco de los fragmentos estudiados con microscopio petrográfico las inclusiones predominantes se diferencian por su naturaleza y/o baja representación de los sedimentos analizados: a) tres ejemplares ordinarios, uno de ellos con cristaloclastos de turmalina, otro con litoclastos graníticos y el último con muscovita; b) un fragmento ante con muscovita y litoclastos graníticos; c) un fragmento tricolor con cantidades significativas de litoclastos graníticos y metamórficos además de tiesto molido. En cuatro de estos casos están ausentes los litoclastos volcánicos y el material piroclástico, elementos siempre presentes en las arenas del valle.

\section{Caracterización química elemental de las muestras}

Se analizaron 11 muestras de arcillas y 58 ejemplares cerámicos. Estos últimos representan la diversidad tecnológica y composicional identificada previamente a partir del análisis de pastas por lupa binocular y microscopio petrográfico (Puente 2011a). Se incluyeron ejemplares de todos grupos de referencia. Para la selección de la muestra se utilizó el mismo criterio que en los estudios petrográficos explicado párrafos atrás, asegurando de este modo que los fragmentos irradiados pertenecían a piezas diferentes:

- Negro sobre rojo: 16 de La Angostura y 23 de El
Duraznito.

- Ordinario: 4 de La Angostura y 12 de El Duraznito

- Negro sobre crema: 1 de La Angostura y 1 de El Duraznito.

- Ante: 1 de La Angostura.

El porcentaje de matriz e inclusiones no plásticas registrados por conteo de puntos durante el análisis petrográfico en cada uno de los conjuntos irradiados se encuentra entre los siguientes valores:

- Negro sobre rojo: matriz 40\%-71\%, inclusiones no plásticas 24\%-54\%.

- Ordinario: matriz 38\%-62\%, inclusiones no plásticas: 23\%-49\%.

- Negro sobre crema: matriz 50\%, inclusiones no plásticas: $39 \%$.

- Ante: matriz 50\%, inclusiones no plásticas: 39\%.

Las pastas elaboradas con tiesto molido no fueron estudiadas por AANI debido a que cada una de ellas representa una síntesis de más de una pieza cerámica y, por lo tanto, constituyen un palimpsesto composicional.

Las muestras molidas, junto con patrones y muestras control, fueron irradiadas durante 5 horas en el Reactor RA-3, del Centro Atómico Ezeiza. Una vez concluida la irradiación, se realizaron dos mediciones con aproximadamente 7 y 30 días de decaimiento, empleando detectores Ortec de Ge HP (30\% de eficiencia y resolución $1.8 \mathrm{keV}$ para el pico de $1332.5 \mathrm{keV}$ del Co-60), acoplados a un módulo buffer multicanal Ortec 919 E Ethernim. Para la adquisición de espectros gamma se utilizó el programa GammaVision 5.10 y las concentraciones elementales fueron calculadas empleando un programa desarrollado en el laboratorio (Plá y Ratto 2003, 2007).

El análisis permitió determinar 21 elementos: Arsénico (As), Bario (Ba), Cerio (Ce), Cobalto (Co), Cromo (Cr), Cesio (Cs), Europio (Eu), Hierro (Fe), Gadolinio (Gd), Hafnio (Hf), Lantano (La), Lutecio (Lu), Rubidio (Rb), Antimonio (Sb), Escandio (Sc), Samario (Sm), Tantalio (Ta), Terbio (Tb), Torio (Th), Uranio (U) e Iterbio (Yb). Para control de calidad de los datos obtenidos, se analizó el material de referencia certificado GBW07405 (Suelo) del Instituto de Exploración Geofísica y Geoquímica de China. La comparación de los valores hallados experimentalmente con los de referencia resultó satisfactoria.

Los análisis estadísticos de los resultados analíticos fueron realizados utilizando el programa SPSS 15.0. Para los gráficos de dispersión y las elipses de confianza se empleó el programa Statistica 8.0. En primer lugar, se realizó estadística descriptiva con los resultados de los 21 elementos químicos determinados para analizar su comportamiento y las características de las distribuciones. Se calculó el valor medio, la desviación estándar, la varianza, la asimetría y la curtosis. Posteriormente, mediante la aplicación de técnicas estadísticas multivariadas se estudió 
la relación composicional entre las muestras analizadas. Para ello, de los 21 elementos químicos determinados sólo 13 (Ce, Co, Cr, Cs, Eu, Fe, Hf, La, Lu, Rb, Sc, Sm, e Yb) fueron considerados para la evaluación, descartando a posteriori el Th por tener un aporte semejante a dos de los componentes hallados. Los criterios utilizados para seleccionar estos los elementos fueron que el valor de la incertidumbre analítica de los resultados debía ser inferior al $15 \%$ y que presentaran un porcentaje de datos faltantes o por debajo del límite de detección inferior al $10 \%$. Previo a la evaluación de los resultados analíticos y para disminuir el posible sesgo introducido por las grandes diferencias de magnitud entre los elementos mayoritarios y traza, se aplicó una transformación logarítmica en base 10 a todos los valores de las concentraciones.

\section{Perfil químico multielemental de la cerámica}

El primer objetivo fue observar la relación composicional de la cerámica, es decir, detectar semejanzas y/o diferencias entre los ejemplares a partir de los resultados analíticos, considerando a su vez sus características estéticas y el sitio en el que fueron recuperados. Para ello, se realizó un análisis de factores empleando el método de análisis de componentes principales (ACP) con rotación Varimax con las 58 muestras y los valores de concentración correspondientes a los 13 elementos químicos mencionados, transformados a valores logarítmicos y se obtuvo una matriz de correlación de la cual se extrajeron los componentes principales y los autovalores (Fernández 2001; Mangeaud 2004). Del análisis surgieron tres componentes que explican el $81,55 \%$ de la varianza total.

El componente 1 expresa el 47,05\% de la varianza y está dominado por los elementos metálicos Fe, Sc, Co y Cr y por las tierras raras Eu y Ce. El componente 2 representa el $21,82 \%$ de la varianza y está dominado por tierras raras $\mathrm{Yb}, \mathrm{Lu}, \mathrm{Sm}$ y La y también por una contribución importante de $\mathrm{Ce}$ y $\mathrm{Hf}$, elemento predominante en el componente 1. El componente 3 expresa el 12,67\% de la varianza y presenta aportes de dos elementos alcalinos, $\mathrm{Rb}$ y Cs. Los elementos predominantes en los componentes 1 y 2 - tierras raras y elementos metálicostienden a concentrarse en la arcilla, a diferencia del Rb y Cs (componente 3) que estarían asociados al material antiplástico. Tabla 3.

A continuación se presenta el gráfico de dispersión de los componentes 1 vs. 2 en donde se diferencian los ejemplares analizados según el grupo de referencia estético al que pertenecen (Figura 4). Se observa un grupo principal, delimitado por una elipse con un nivel de confianza de $95 \%$, que comparte un mismo perfil químico multielemental y está conformado por cantidades semejantes de cerámica procedente de los sitios La Angostura y El Duraznito. Estos ejemplares corresponden a la mayoría de la cerámica negro sobre

\begin{tabular}{llcc}
\hline \multicolumn{4}{c}{ Componente } \\
& 1 & 2 & 3 \\
\hline $\mathrm{Fe}$ &, 974 & & \\
$\mathrm{Sc}$ &, 932 & &, 111 \\
$\mathrm{Co}$ &, 924 & & \\
$\mathrm{Eu}$ &, 813 &, 315 &,- 181 \\
$\mathrm{Cr}$ &, 752 & & \\
$\mathrm{Ce}$ &, 681 &, 613 & \\
$\mathrm{Yb}$ & &, 916 & \\
$\mathrm{Lu}$ & &, 913 & \\
$\mathrm{Sm}$ &, 559 &, 736 & \\
$\mathrm{Hf}$ & &, 730 &,- 222 \\
$\mathrm{La}$ &, 605 &, 708 & \\
$\mathrm{Rb}$ &,- 104 & &, 944 \\
$\mathrm{Cs}$ & &,- 186 &, 876 \\
\hline
\end{tabular}

Tabla 3. Matriz de componentes rotados.

Table 3. Matrix rotated components.

rojo (Belén), a un ejemplar negro sobre crema y a la mitad de los ejemplares del conjunto ordinario analizados. Dada esta homogeneidad se infiere que las piezas a las que dichos fragmentos pertenecieron fueron elaboradas con materias primas procedentes de una misma área de aprovisionamiento. Asimismo, algunos ejemplares se alejan del conjunto delimitado por la elipse, lo que estaría indicando el probable uso de otras arcillas para su elaboración: A) 45-467 (negro sobre crema, El Duraznito) y 42-88 (ante, La Angostura), ambos se asocian entre sí pero se diferencian de la mayoría de los ejemplares a partir del segundo componente. B) 46-1041 (ordinario, El Duraznito), se diferencia a partir de los componentes 1 y 2. C) 32-142 (ordinario, La Angostura) es el ejemplar que más se diferencia de la dispersión central en relación con los primeros dos componentes. D) 45-844 (ordinario, El Duraznito) se diferencia principalmente a partir del componente 1 .

En síntesis, los resultados del perfil químico multielemental de la muestra cerámica analizada permiten decir que: 1) El conjunto ordinario presenta mayor variabilidad química multielemental que el conjunto Belén, por lo cual se infiere que para la elaboración del primero se utilizaron mayor cantidad de fuentes de arcilla. 2) La mayoría de los fragmentos Belén, gran parte de los ordinarios y uno negro sobre crema comparten el mismo perfil químico multielemental indicando que fueron elaborados con materias primas de la misma área de aprovisionamiento. 3) Ejemplares de ambos sitios poseen un perfil composicional multielemental homólogo, a partir de los cual se plantea que las materias primas utilizadas para elaborar dicha alfarería proceden de la misma región.

\section{Perfil químico multielemental de las arcillas}

En segundo lugar, se comparó la composición de las arcillas ( $\mathrm{N}$ : 11) entre sí para determinar cómo se relacionaban composicionalmente. La relación entre ellas con respecto a los 13 elementos químicos considerados se evaluó a partir de un análisis de cluster jerárquico, usando el método de Ward y la distancia Euclídea al 


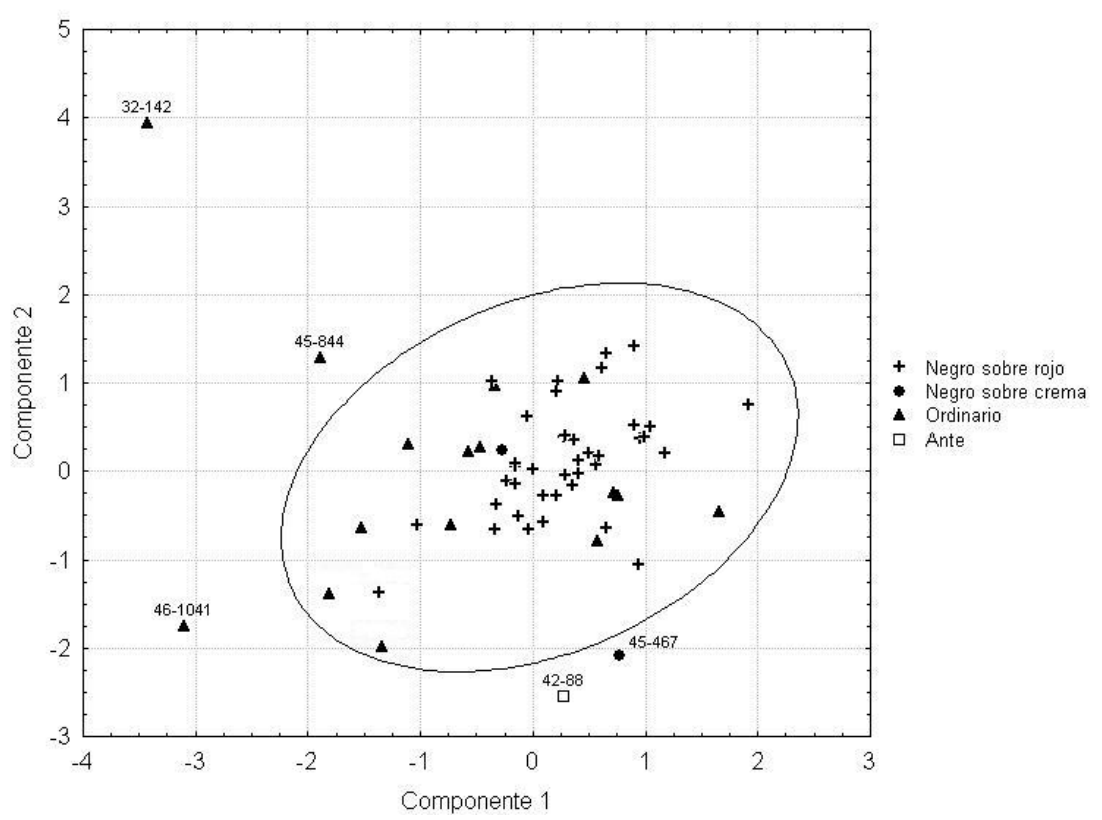

Figura 4. Representación gráfica del ACP. Discriminación por conjunto cerámico.

Figure 4. Graphical representation of the ACP discrimination by ceramic set.

cuadrado. En el dendograma se observa un cluster principal conformado por nueve arcillas y, por otra parte, dos arcillas diferentes entre sí y distintas de dicho grupo (Ar.7 y Ar. 10-LT1). A su vez, dentro del grupo principal se distinguen las siguientes relaciones de mayor semejanza: 1) Ar.2 y Ar.4; 2) Ar.1, Ar.3 y Ar.9 y 3) Ar. 5, Ar.6, Ar8 y Ar.10-LT4 (Figura 5).

Estos resultados muestran importantes semejanzas químicas entre las muestras arcillosas recolectadas en distintos sectores del valle, excepto Ar. 7 y Ar. 10LT1. Considerando las concentraciones elementales determinadas, la primera de ellas se diferencia del resto por contener concentraciones más bajas de $\mathrm{Rb}, \mathrm{Cr}$ y $\mathrm{Cs}$ y más altas de U, La y Ce. En cambio, Ar.10-LT1 posee concentraciones mayores de As y Cr. Esta última y Ar. 10LT4 fueron extraídas del mismo barranco pero de estratos diferentes y a pesar de ello presentan perfiles químicos multielementales distintos. Dada la particularidad de estos resultados, se repitió el análisis para la muestra LT1 y se corroboraron los datos obtenidos en un primer momento, destacando las diferencias químicas de esta arcilla en la concentración de los elementos mencionados.

Relación entre el perfil químico multielemental de las cerámicas y las arcillas

Con el propósito de estudiar la relación entre las arcillas y la cerámica y establecer inferencias en torno a la procedencia local o alóctona de las piezas estudiadas, se procesaron los datos composicionales utilizando ACP. Así, la muestra se integra por los 69 casos (11 arcillas y 58 cerámicas) y se consideran los 13 elementos químicos mencionados previamente. De la matriz de

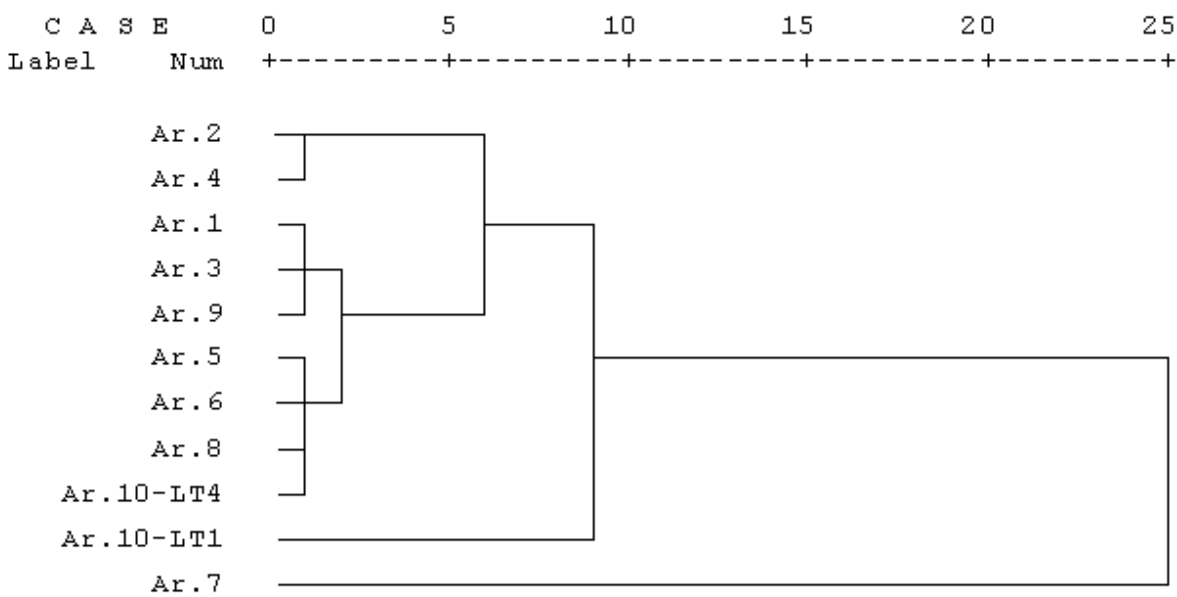

Figura 5. Dendograma, perfil químico multielemental de las muestras de arcilla.

Figure 5. Dendogram multi-elemental chemical profile of the clay samples. 


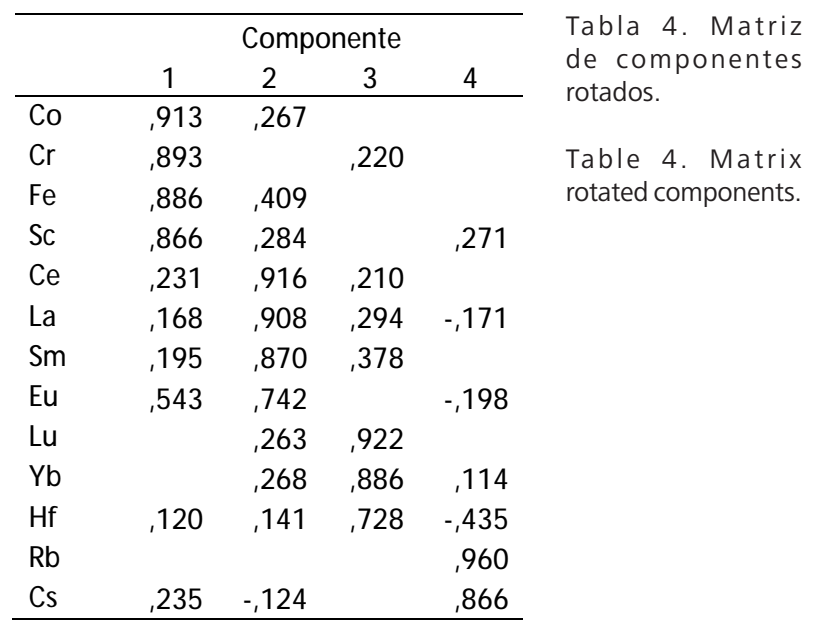

correlación obtenida a partir de los valores transformados a logaritmos se extrajeron los componentes principales y los autovalores. También se utilizó el método de rotación de Varimax con Kaiser. Del análisis surgen cuatro componentes que explican el $89,76 \%$ de la varianza total.

El primer componente expresa el $46,31 \%$ de la varianza y está dominado por los elementos metálicos de transición $\mathrm{Co}, \mathrm{Cr}$, Fe y Sc, los cuales tienden a concentrarse en la fracción arcilla. El componente 2 representa el 20,39\% de la varianza y en él predominan tierras raras livianas: $\mathrm{Ce}, \mathrm{La}$, Sm y mediana: Eu. El componente 3 expresa el 13,71\% de la varianza y está dominado por los elementos $L u, Y b$, los cuales también son tierras raras de las denominadas pesadas y Hf. Por último, el componente 4 expresa el $9,35 \%$ de la varianza y lo integran el $\mathrm{Rb}$ y Cs, elementos alcalinos generalmente asociados al material antiplástico. (Figura 6) (Tabla 4).

Las arcillas Ar.10LT-1 y Ar.7 presentan un perfil químico multielemental que las diferencia entre sí, del resto de las arcillas y también de la cerámica. Este aspecto indica que no fueron utilizadas en la manufactura de los ejemplares estudiados. Con respecto a la distribución de las muestras dentro de la elipse, en relación con componente 1, nueve arcillas son similares entre sí y se asocian con el perfil químico multielemental de la mayoría de las cerámicas representadas en la nube de puntos principal. Con respecto al componente 2 , si bien las arcillas están cercanas entre sí se observa que Ar.2, Ar.4, Ar.8 y LT4 se vinculan a la mayoría de la cerámica que integra la nube más densa de puntos y, Ar.3, Ar.1, Ar.6, Ar.9 y Ar.5 se asocian con ejemplares que están más dispersos. De este modo, si bien el perfil químico elemental de las arcillas no presenta una coincidencia plena con el de la cerámica, la pertenencia a la elipse de confianza y la cercanía entre los puntos permiten plantear que el valle del Bolsón formó parte del área de aprovisionamiento de materias primas para la elaboración de la mayoría de la alfarería analizada.

Por último, cabe destacar que cinco ejemplares quedan fuera de la elipse de confianza. Cuatro de ellos pertenecen al conjunto ordinario y uno es Belén. Solo un caso ordinario (el 32-142) se diferencia petrográficamente del conjunto mayoritario.

\section{Síntesis y discusión final}

La manufactura alfarera es un proceso de producción que requiere la transformación de las materias primas utilizadas para obtener el objeto deseado. Dado que este cambio no solo es formal, como por ejemplo el que ocurre en la talla de una herramienta lítica, la interpretación sobre su procedencia no es sencilla. Los ceramistas pueden mezclar distintas arcillas, tamizarlas, incorporarles antiplásticos de diversa naturaleza, estos aspectos más los cambios ocurridos en la cocción según el tipo de tecnología utilizada y la temperatura alcanzada, tienen como consecuencia la elaboración de un objeto
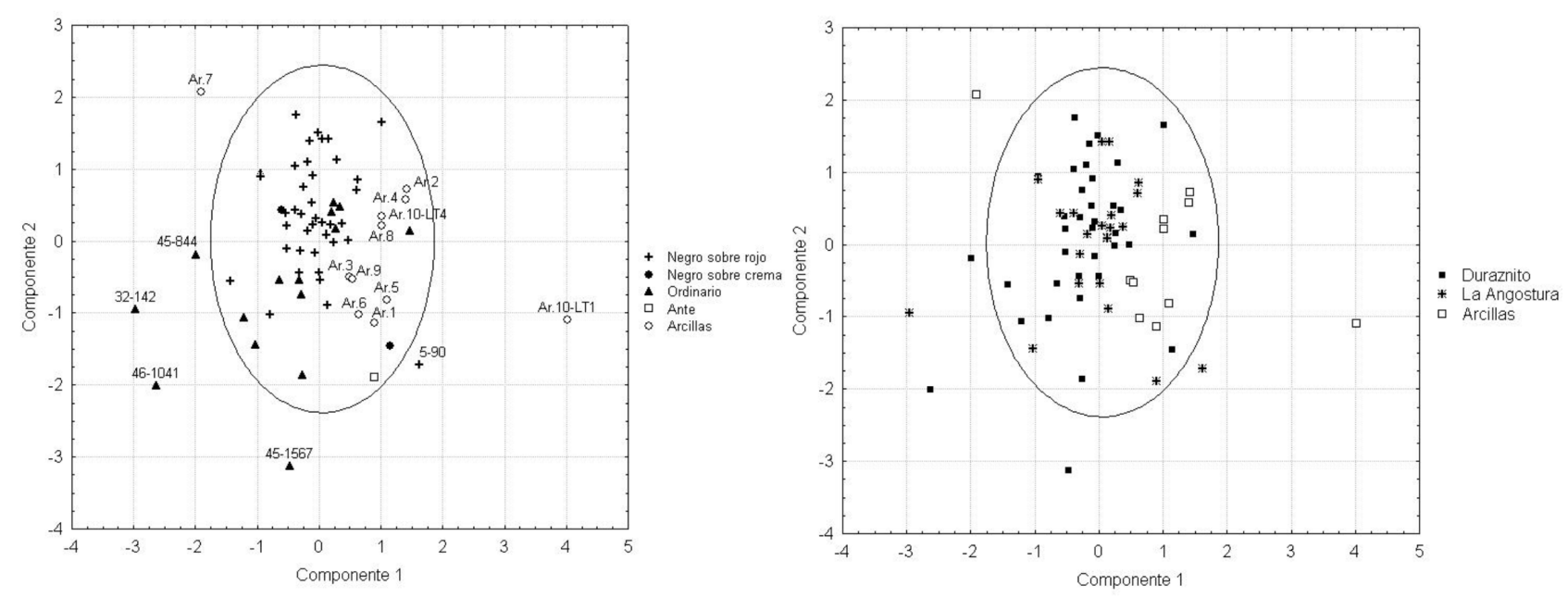

Figura 6. Representaciones gráficas del ACP. Discriminación de muestras por conjunto cerámico, fuente de arcilla y sitio.

Figure 6. Graphical representations of the ACP. Sample discrimination by ceramic assemblage, source of clay and site. 
química y mineralógicamente complejo. Por este motivo, los estudios de procedencia de cerámica arqueológica requieren de un acercamiento metodológico integral que combine información química y mineralógica de las piezas y también su comparación con materias primas locales (Bishop et al. 1982; Tite 1999).

En el valle del Bolsón hasta el momento no se recuperó evidencia primaria de producción cerámica, esto es, bollos de arcillas, hornos, piezas sin cocer, entre otros. Sin embargo, la ausencia de este registro no implica que dicha actividad no se haya desarrollado. A partir del muestreo realizado para detectar depósitos de arcillas y sedimentos no plásticos y las posteriores tareas de experimentación se generó un banco de datos sobre las materias primas disponibles y adecuadas por su calidad para la elaboración de alfarería en la región. Los resultados alcanzados en este sentido, evidenciaron la coexistencia de depósitos o afloramientos de arcilla potencialmente utilizables ubicados en distintos sectores del valle (Puente 2011a). Los análisis petrográficos y por AANI realizados sobre la cerámica y los sedimentos muestreados se complementaron entre sí para establecer inferencias sobre la procedencia local o alóctona de un número importante de fragmentos, cada uno de los cuales representa una pieza diferente. Los datos generados por ambas técnicas analíticas son coherentes entre sí. Se destacan la homogeneidad composicional de un importante número de piezas y, además, su asociación con ciertas materias primas locales. Asimismo, más allá de las diferencias logísticas y estratégicas que tuvieron ambos asentamientos estudiados poseen similitudes en la procedencia de la vajilla utilizada.

Con respecto a las arenas muestreadas los estudios petrográficos permitieron identificar diferencias entre distintos sectores de la región y reconocer semejanzas con el material antiplástico presente en la cerámica. El resultado más destacado es que detectamos que la arena que acarrea el río El Bolsón (S.4) posee la misma variabilidad petrográfica que la identificada en la mayoría de los ejemplares cerámicos analizados. Por este motivo, se concluye que este sedimento $y$, posiblemente, en muchos casos en combinación con el S.2, fueron utilizados en la elaboración de gran parte de la cerámica recuperada en los sitios.

Específicamente, la mayoría de la cerámica Belén forma un conjunto homogéneo en función de la petrografía de sus pastas y al perfil químico multielemental de las arcillas con las que fue elaborada. Además, se relaciona con la petrografía de las arenas locales (S.4 y S.2) y con el perfil químico de los distintos depósitos arcillosos del valle. Solo un ejemplar de este estilo recuperado en el sitio el Duraznito posee una petrografía coherente a la mayoría de las piezas de su mismo grupo pero se aleja de la elipse central en el ACP con datos de AANI, lo que indicaría que fue elaborado con otra materia prima aún no detectada en la región.

De la cerámica ordinaria analizada por activación neutrónica, cuatro ejemplares se diferencian de la mayoría de la alfarería en su perfil químico multielemental. Dado que estas muestras se apartan de la tendencia general observada en los conjuntos estudiados consideramos que su procedencia es alóctona, o bien fueron elaboradas con depósitos arcillosos aún no detectados en el valle. Igualmente, cabe destacar que hasta el momento se dispone de información petrográfica para dos de estos casos y solo uno de ellos posee una petrografía claramente distinta.

En síntesis, a partir de la combinación de los análisis realizados se concluye que un grupo mayoritario de piezas recuperadas en La Angostura y El Duraznito correspondientes principalmente a las reconocidas como Belén, en menor medida a cerámica ordinaria (sin tiesto molido), dos ejemplares negro sobre crema y uno ante fueron elaborados con materias primas identificadas en el Valle del Bolsón.

Por último, los antecedentes disponibles hasta el momento sobre lugares de elaboración de alfarería de estilo Belén provenían de la región de Abaucán. Allí estas piezas fueron elaboradas junto a cerámica ordinaria y de estilos Sanagasta y Abaucán. Los resultados generados en este estudio son un importante avance en el tema de la producción alfarera a escala suprarregional dado que evidencian que existieron distintos locus de producción de piezas asociadas a un mismo estilo iconográfico.

Mar del Plata, 3 de Septiembre de 2013

\section{Agradecimientos}

Las investigaciones fueron financiadas por ANCYT (PICT 1657), CONICET (PIP 112-200801-00285) y UBACYT (F785 20020100100182).

\section{Bibliografía}

Bishop, R. L., R. Lands y G. R. Holley. 1982. Ceramic compositional analysis in archaeological perspective. M.B. Schiffer (Ed.), Advances in Archaeological Method and Theory, Vol. 5: 275-330. Academic Press, New York y London.

Bishop, R. L. 2003. Instrumental Neutron Activation Analysis of Archaeological ceramics: progress and challenge. Nuclear Analitical Techniques in Archaeological Investigations. Technical Report Series $n^{\circ}$ 416: 35-44. International Atomic Energy Agency, Vienna.

Cremonte, B., A. Ramírez y S. M. Peralta. 2007. Identificación y caracterización de manufacturas cerámicas no locales del pukará de Volcán. Petrografía de pastas y Fluorescencia de Rayos. M. B. Cremonte y N. Ratto (Eds.), Cerámicas arqueológicas. Perspectivas arqueométricas para su análisis e interpretación, 49-72. Universidad Nacional de Jujuy, Jujuy. 
De La Fuente, G. A. 2007. "Producción y tecnología cerámica en Batungasta: estandarización, especialización y procedencia. (Valle de Abaucán, Dpto. Tinogasta, Pcia. de Catamarca, Argentina)". Facultad de Ciencias Naturales y Museo, Universidad Nacional de La Plata, Argentina, p. 518. Tesis de doctorado. Biblioteca Florentino Ameghino, FCEyM, UNLP.

De La Fuente, G. A. 2010. Tinajas, ollas y yuros: producción de alfarería durante el Período Tardío (ca. $A D$ 900- $A D$ 1200) en Watungasta (Dpto. Tinogasta, Catamarca, Argentina. M. C. Páez y G. A. De La Fuente (Eds.), La cerámica arqueológica en la materialización de la sociedad. Transformaciones, metáforas y reproducción social, 91-104. BAR-British Archaeological Series 2010 - Southamerican Archaeological Series, Londres.

Dobres, M. A. 1999. Of Paradigms and Ways of Seeing. Artefact Variability as if People Matted. E. Chilton (Ed.) Material Meanings: Critical Approaches to the Interpretation of Material Culture, 7-23. Salt Lake City, Foundations of Archaeological Inquiry, The University of Utah Press, Utah.

Feely, A. 2010. “Estilos tecnológicos y tradiciones cerámicas del Bolsón de Fiambalá (Dpto. Tinogasta, Catamarca)". Facultad de Filosofía y Letras, Universidad de Buenos Aires, Argentina, p. 377. Tesis de doctorado. Biblioteca central, FFyL, UBA.

Feely, A. 2011. Caracterización de estructuras de doble cámara para la cocción de artefactos cerámicos en La Troya (Tinogasta, Catamarca). Relaciones de la Sociedad Argentina de Antropología, XXXVI: 325-330.

Fernández, F. 2001. El uso del análisis multivariado en Antropología. Boletín Antropológico, año 20, vol 1, № 51: 5-18. Universidad de Los Andes, Mérida.

González Bonorino, F. 1950. Geología y petrografía de las hojas $12 d$ (Capillitas) y 13d (Andalgalá). Ministerio de Industria y Comercio de la Nación, Buenos Aires.

Iucci, M. E. 2013. Petrografía de la fracción arena en la cerámica Belén. Aporte desde el análisis composicional y textural. M. Ramos, M. Lanza, V. Helfer, V. Pernicone, F. Bognanni, C. Landa, V, Aldazabal y M. Fernández (Eds.) Arqueometría Argentina. Estudios pluridisciplinares, cap. 11: 175-193. Aspha, UNLU, Buenos Aires.

Korstanje, M. A. 2005. "La organización del trabajo en torno a la producción de alimentos en sociedades agropastoriles formativas (Provincia de Catamarca, República Argentina)." Instituto de Arqueología y Museo, Facultad de Cs. Naturales e Inst. M. Lillo, Universidad Nacional de Tucumán, Argentina, p. 405. Tesis de doctorado. Biblioteca del IAM, UNT.

Lemonnier, P. 1992. Elements for an Anthropology of Technology. Museum of Anthropology, Michigan.

Mangeaud, A. 2004. La aplicación de técnicas de ordenación multivariada en la entomología. Revista de la Sociedad Entomológica Argentina, 63 (3-4): 1-10.

Marchegiani, M., V. Palamarczuk y A. Reynoso. 2009. Las urnas negro sobre rojo tardías de Yocavil (Noroeste Argentino). Reflexiones en torno al estilo. Boletín del Museo Chileno de Arte Precolombino 14 (1): 69-98.
Orgaz, M., A. Feely y N. Ratto. 2007. La cerámica como expresión de los aspectos socio-políticos, económicos y rituales de la ocupación Inka en la puna de Chaschuil y el valle de Fiambalá (Departamento Tinogasta, Catamarca, Argentina). A. E. Nielsen, M. C. Rivolta, V. Seldes, M. M. Vázquez y P. H. Mercolli (Comp.), Procesos sociales prehispánicos en el sur andino. La vivienda, la comunidad y el territorio, 237-256. Editorial Brujas, Córdoba.

Páez, M. C. 2010. “Tecnología alfarera del último milenio de ocupación aborigen del valle de Tafí (Prov. de Tucumán)". Facultad de Ciencias Naturales y Museo, Universidad Nacional de La Plata, Argentina, p. 773. Tesis de doctorado. Biblioteca Florentino Ameghino, FCEyM, UNLP.

Palamarczuk, V. 2008. Un análisis de la cerámica arqueológica de cuatro sitios en el bajo de Rincón Chico. M. N. Tarragó, L. R. González (Eds.), Estudios arqueológicos en Yocavil, cap 2: 1980. Asociación de Amigos del Museo Etnográfico, Buenos Aires.

Palamarczuk, V. 2011. Un estilo y su época. El caso de la cerámica Famabalasto Negro grabado del Noroeste Argentino. BAR International series 2243. Archeopress, Oxford.

Plá, R. 2009. El rol del Análisis por Activación Neutrónica en estudios arqueométricos. O. M. Palacios, C. Vázquez, T. Palacios y E. Cabanillas (Eds.), Arqueometría Latinoamericana, vol. 1: 47-52.

Plá R., N. Ratto. 2003. Provenance archaeological studies of ceramic raw materials and artifacts using instrumental neutron activation analysis: the cases of Chaschuil and Bolsón de Fiambalá (Catamarca, Argentina ). Technical Report Series $N^{\circ}$ 416: 45-69. Nuclear Analytical Techniques in Archaeological Investigation, IAEA, Vienna.

Plá, R.R. y N. Ratto. 2007. Archaeometry at the Argentine National Atomic Energy Commission: characterization of Argentine Northwestern pottery. Archaeometry 49 (2): 413-420.

Puente, V. 2011a. "Prácticas de producción alfarera en el Valle del Bolsón (Belén, Catamarca): materias primas y modos de hacer ca. 900-1600 D.C.". Facultad de Filosofía y Letras, Universidad de Buenos Aires, Argentina, p. 540. Tesis de doctorado. Biblioteca central, FFyL, UBA..

Puente, V. 2011b. Prácticas de producción alfarera durante el tardío prehispánico en el valle del Bolsón. Un aporte desde la tecnología cerámica del sitio El Duraznito (Belén, Catamarca, Argentina). Arqueología 18: 101-129.

Puente, V. 2012a. Lo que "oculta" el estilo: materias primas y modos de hacer en la alfarería Belén. Aportes desde la petrografía de conjuntos cerámicos del Valle del Bolsón (Belén, Catamarca, Argentina). Estudios Atacameños 43: 71-94.

Puente V. 2012b. "Atravesando fronteras": prácticas e identidades sociales compartidas durante el tardío prehispánico en el área valliserrana del NOA. Una discusión desde la alfarería ordinaria del valle del Bolsón. Relaciones de la Sociedad Argentina de Antropología, XXXVII (1): 65-87.

Puente, V. y L. Quiroga. 2007. Percepción de la forma, variabilidad del conjunto estilístico Belén (colección Schreiter). Mundo de Antes 5: 157-184. 
Quiroga, L. 2002. "Paisaje y relaciones coloniales en el Valle de Cotahau. Del tardío a la ocupación colonial". Facultad de Geografía e Historia, Universidad de Sevilla, España, p. 230. Tesis de doctorado. Biblioteca del Museo Etnográfico, FFyL, UBA.

Quiroga, L. 2010. Transformaciones en los modos de habitar: reconstruir los muros, resignificar los espacios (siglos XVI-XVII). Trabajo presentado en XVII Congreso Nacional de Arqueología Argentina. Mendoza, Argentina. MS.

Quiroga, L. 2011. Al Abrigo de sus Huaycos: Narrar la geografía, habitar los espacios, interpretar las prácticas. M.E. Albeck, B. Cremonte y M. Ruiz (Eds.) Sociedades Precolombinas Surandinas. TANOA II, Universidad Nacional de Jujuy, en prensa.

Quiroga L. y S. Martínez. 2013. Vivir en los cerros. Arquitectura y entorno en el Valle del Bolsón ScaBe 4(2): La Peña del Corral o El Duraznito. Trabajo presentado en el XVIII Congreso Nacional de Arqueología Argentina. MS.

Ratto, N., M. Orgaz y R. Plá. 2002a. Producción y distribución de bienes cerámicos durante la ocupación Inca entre la región puneña de Chauschuil y el valle de Abaucán (Dpto. Tinogasta, Catamarca). Relaciones de la Sociedad Argentina de Antropología XXVII: 271-301.

Ratto, N., M. Orgaz, G. De La Fuente y R. Plá. 2002b. Ocupación de pisos de altura y contextos de producción cerámica durante el Formativo: el caso de la región puneña de Chaschuil y su relación con el Bolsón de Fiambalá (Dpto. Tinogasta, Catamarca, Argentina). Estudios Atacameños 24: 51-69.

Ratto, N.; M. Orgaz, y R. Plá. 2004. La explotación del alfar de la Troya en el tiempo: casualidad o memoria (Departamento Tinogasta, Catamarca, Argentina). Chungará 36 (2): 351-363.

Ratto, N., A. Feely y R. Plá. 2007. La producción alfarera en el bolsón de Fiambalá (departamento Tinogasta, Catamarca) y su alcance extra-regional. M. B. Cremonte y N. Ratto (Eds.) Cerámicas arqueológicas. Perspectivas arqueométricas para su análisis e interpretación, 123-146. EdiUnju, Jujuy.

Ratto, N. y R. Plá. 2009. Variaciones en la composición química multielemental de materias primas cerámicas crudas y cocidas (Tinogasta, Catamarca, Argentina). Libro de resúmenes $3^{\circ}$ Congreso Argentino de Arqueometría: 48. Córdoba.

Ratto, N., A. Feely y R. Plá. 2010. 1000 años de producción alfarera en el Bolsón de Fiambalá: cambios y continuidades (Catamarca, Argentina). Actas del XVII Congreso Nacional de Arqueología chileno, acta 2: 789-846. Sociedad Chilena de Arqueología.

Rice, P. 1987. Pottery analysis, a sourcebook. The University of Chicago Press. Chicago y London.

Rye, O. 1981. Pottery technology. Principles and reconstruction. Manuals on Archaeology, 4. Taraxacum Incorporated, Washington.

Shepard, A. 1957. Ceramics for the archaeologist. Carnegie Institution of Washington, Washington.

Stoltman, J. B. 2001. The Rol of Petrography in the Study of Archaeological Ceramics. P. Goldberg, V. T. Holliday y C. Reid Ferring (Eds.), Earth Sciences and Archaeology: 297-326. Kluwer Academic, Plenum Publishers, New York.

Tite, M.S. 1999. Pottery production, distribution, and consumption-the contribution of the physical sciences. Journal of Archaelogical Method and Theory, 6 (3): 181-233.

Turner, J. C. 1973. Descripción geológica de la hoja 11d, Laguna Blanca Provincia de Catamarca. Ministerio de Industria y Minería., Buenos Aires.

Zagorodny, N., M. Morosi, M.E. lucci y F. Wynveld. 2010. Estudios composicionales de las pastas de la cerámica tardía de distintos sitios del Valle de Hualfín (Belén, Catamarca). Arqueología 16: 12-149. 